\title{
MULTIDIMENSIONALIDADE DOS DIREITOS FUNDAMENTAIS E SUA INFLUÊNCIA NO PROCESSO
}

Hamilton da Cunha IRIBURE JÚNIOR ${ }^{1}$

Gustavo Silva XAVIER ${ }^{2}$

ISSUE DOI: $10.21207 / 1983.4225 .702$

\begin{abstract}
RESUMO
Os direitos fundamentais são frutos de lutas históricas ocorridas em contextos de dominação e se apresentam como normas que limitam a atuação estatal. Como ponto peculiar desse processo, costuma-se tratar sua evolução histórica por meio das denominadas dimensões dos direitos fundamentais. No entanto, com o progresso da ciência e diversos outros fatores, surgem cada vez mais necessidades
\end{abstract}

\footnotetext{
${ }^{1}$ Doutor em Direito pela Pontifícia Universidade Católica de São Paulo - PUC/SP (2009), aprovado com distinção e reconhecimento da pesquisa. Mestre em Direito pela Pontifícia Universidade Católica de São Paulo PUC/SP (2005). Especialista em Direito Processual Civil pela Universidade de Cuiabá UNIC (2002). Graduado em Direito pela Universidade Federal de Mato Grosso UFMT (2000). Mestre em Engenharia Civil pela Pontifícia Universidade Católica do Rio de Janeiro PUC/Rio (1991). Graduado em Engenharia Civil pela Universidade Federal de Mato Grosso - UFMT (1988). Atualmente é Professor Adjunto da Graduação e do Programa de Mestrado da Faculdade de Direito do Sul de Minas (FDSM). É associado do Conselho Nacional de Pesquisa e Pós-Graduação em Direito (CONPEDI). Currículo Lattes: http://lattes.cnpq.br/9009611714454221 E-mail: hamilton.adv@terra.com.br

${ }^{2}$ Mestre em Direito pela Faculdade de Direito do Sul de Minas (FDSM). Docente Universitário. Pesquisador CNPq - Grupo de Pesquisa SAPERE AUDE.
} 
humanas marcadas, não raras vezes, por conflitos e novos problemas gerados pela complexidade social, emergindo novos direitos que colocam em desafio a dogmática jurídica tradicional. Desse modo, por meio do método analítico documental, este trabalho tem por objetivo propiciar reflexões adicionais à temática da dimensionalidade dos direitos fundamentais em face do surgimento de novos direitos fundamentais, demonstrando sua estreita relação com os mecanismos processuais aptos a tutelá-los. Assim, as novas formas de direitos desafiam a dogmática jurídica tradicional e suas modalidades individualistas de tutela.

Palavras-chave: direitos fundamentais; multidimensionalidade; novos direitos; processo.

\begin{abstract}
Fundamental rights are the fruits of historical struggles that take place in contexts of domination and present themselves as norms that limit state performance. As a peculiar point of this process, one usually treats its historical evolution through the denominated dimensions of the fundamental rights. However, with the progress of science and many other factors, human needs are increasingly being marked, not infrequently, by conflicts and new problems generated by social complexity, with the emergence of new rights that challenge traditional legal dogmatics. Thus, through the documentary analytical method, this work aims to provide additional reflections on the issue of the dimensionality of fundamental rights in the face of the emergence of new fundamental rights, demonstrating its close relationship with the procedural mechanisms apt to tutelá- the Thus, the new forms of rights challenge traditional legal dogmatics and their individualistic modes of guardianship.
\end{abstract}

Keywords: fundamental rights; multidimensionality; new rights; process.

\title{
INTRODUÇÃO
}

Os direitos fundamentais se apresentam como garantias do cidadão contra interferências indevidas, seja por parte da atuação estatal, seja por parte de particulares. São, pois, frutos de uma longa história de dominação e de busca da sociedade pela limitação do poder do Estado, sendo, inclusive, aplicáveis no âmbito das relações privadas (eficácia horizontal). Para demonstrar seu surgimento ao longo dos anos, especialmente quando da consagração das Declarações de Direito, costuma-se tratar o tema sob o prisma das chamadas gerações ou dimensões dos direitos fundamentais (Cf. BONAVIDES, 2013), vinculadas, inicialmente, aos lemas da Revolução Francesa: liberdade (primeira dimensão), igualdade (segunda dimensão) e fraternidade (terceira dimensão).

No entanto, com o avanço da ciência e com o aumento das necessidades humanas, que dão ensejo ao surgimento de outros direitos até então não tutelados pela norma de direito fundamental, surge a necessidade de se criarem novas classificações e, por conseguinte, novos instrumentos de tutela aos novos direitos. Assim, a dogmática tradicional vem dando ensejo a outros reenquadramentos em face das dimensões dos direitos fundamentais, sendo mais recente a menção à quarta e quinta dimensões 
(BONAVIDES, 2013, p. 589-597), para se referir, essencialmente, aos novos direitos fundamentais surgidos recentemente (no caso, democracia, pluralismo, informação e paz, respectivamente).

Sem deixar de reconhecer a importância e o mérito em tal sistemática, este trabalho tem por objeto o estudo das dimensões dos direitos fundamentais e de sua influência na norma de Direito Processual, de modo a trazer reflexões adicionais que possam contribuir para o aperfeiçoamento do tema. Para tanto, toma como premissa o fato de que, no atual estágio da ciência, a expressão correta acerca da evolução histórica dos direitos fundamentais e suas diversas concepções deve se referir à sua multidimensionalidade, uma vez que os direitos fundamentais formam um sistema harmônico, coerente e indissociável, fato que importa na impossibilidade de compartimentalização destes.

Isso porque a fragmentação comumente adotada em relação aos direitos de quarta e quinta dimensões contempla, na verdade, direitos tipicamente individuais, sociais e transindividuais, a depender do modo como são tutelados. Assim, os direitos decorrentes da biotecnologia e da bioengenharia, por exemplo, podem gerar direitos sociais, os quais podem dizer respeito ao consumidor quando se tratar de alimentos modificados (BRANDÃO, 2000, p. 126), bem como causar danos ao meio ambiente (direito de terceira dimensão).

$\mathrm{Na}$ mesma dicção, os direitos atinentes à realidade virtual (que para alguns são classificados como de quinta dimensão) podem gerar danos de cunho estritamente individual, como no caso da inserção de vírus em computador privado, ou lesões coletivas, no caso de direito afeto à coletividade, a exemplo de danos advindos na rede mundial de computadores.

Parte-se, também, da ideia de que jurisdição e processo são dois institutos indissociáveis (JÚNIOR, 2013, p. 227), haja vista que o direito à jurisdição e ao processo são instrumentos indispensáveis à garantia dos direitos fundamentais. Nesse vértice atua também a noção de dignidade humana, porquanto não é possível garantir os ditames do devido processo legal sem se assegurar, em contrapartida, outros direitos humanos (fundamentais).

Assim sendo, por meio da metodologia analítica documental, este artigo objetiva analisar a evolução histórica dos direitos fundamentais (dimensões) e sua influência no processo, procurando demonstrar que, na medida em que vão surgindo novos direitos, há a necessidade de se criarem instrumentos necessários à garantia destes. Para isso, na primeira parte, 
analisar-se-ão os elementos necessários à consagração dos direitos fundamentais. Posteriormente, com base na doutrina tradicional, far-se-á um pertinente estudo acerca das chamadas dimensões dos direitos fundamentais, de maneira a estabelecer quais os fundamentos de se adotar tal classificação.

Com o objetivo de contribuir ao aprimoramento do tema, propiciamos reflexões críticas a respeito de tal nomenclatura, sugerindo a terminologia multidimensionalidade dos direitos fundamentais. Além disso, como o presente tema está relacionado à evolução histórica dos direitos fundamentais, notadamente pelo surgimento de novos direitos, a partir de referenciais teóricos nacionais e alienígenas, lançamos mão do estudo do art. $5^{\circ}, \S 2^{\circ}$, da Constituição da República, por ser justamente o fundamento do surgimento de novos direitos, por meio da fundamentalidade material destes.

Por fim, diante da inegável relação entre direitos fundamentais e processo, demonstrar-se-á a relação existente entre os direitos fundamentais e o processo, fato que gerou o título do presente artigo - multidimensionalidade dos direitos fundamentais e sua influência no processo - haja vista que a partir do nascimento de novos direitos, faz-se necessário criar instrumentos aptos a tutelá-los. O estudo desses novos direitos exige, pois, pensar novos instrumentos adequados para viabilizar a materialização e garantia de tutela jurisdicional.

\section{ELEMENTOS NECESSÁRIOS PARA O SURGIMENTO DOS DIREITOS FUNDAMENTAIS}

Quando este tema é abordado, é comum apenas se limitar pura e simplesmente à busca de antecedentes históricos sem problematizá-los (Cf. SILVA, 2005, p. 542) e não será este o enfoque dado neste artigo. Muito mais do que isso: o escopo deste trabalho é aferir elementos essenciais ao reconhecimento de tais direitos. Nesse contexto, faz-se necessário percorrer alguns momentos que antecederam e influenciaram o seu reconhecimento em nível do Direito Constitucional, cujo fundamento reside justamente na proteção da dignidade humana e no reconhecimento dos direitos do homem frente ao poderio estatal (na busca pela limitação do poder estatal). 
Desde a antiguidade, especialmente na cultura Greco-romana e no pensamento cristão, já se tinha a ideia de que o ser humano, pelo simples fato de existir, seria titular de alguns direitos naturais (SARLET, 2015, p. 36). No cristianismo, tem-se o acolhimento da dignidade única do homem, que passa a ser a imagem e semelhança de Deus, além da declaração de igualdade entre os homens, pois, conforme Paulo de Tarso (GÁLATAS, 3, 28), "não há judeu nem grego, não há varão nem mulher, pois todos vós sois um em Cristo Jesus".

Lado outro, a Magna Charta Libertatum de 1215, conquanto tenha garantido direitos a determinadas classes, também serviu como ponto de referência a diversos direitos hoje consagrados. Vê-se, aqui, a dicção do princípio da legalidade (cláusulas 16 e 23), das bases do tribunal do júri e do paralelismo entre os delitos e as penas (cláusulas 20 e 21), além do respeito à propriedade privada (cláusulas 30 e 31) e a garantia do devido processo legal (cláusula 39). Trata-se, dessarte, de importante documento que visa garantir, ainda que apenas a determinado grupo, diversos direitos hoje assegurados pela hodierna ordem constitucional.

Ressalta-se também a importância do pensamento de Tomás de Aquino que, aliado à posição anterior, aduz a existência de duas ordens distintas, uma relacionada aos direitos naturais e outra ao direito positivo, porquanto, a desobediência àqueles por parte dos governantes legitimaria o direito de resistência pela população (COMPARATO, 1999, p. 55). Além disso, insta aduzir as importantes declarações de direitos presentes no século XVII, notadamente a Petition of Rights de 1628, o Habeas Corpus Act de 1679, o Bill of Rights, de 1689 e o Establishment Act de 1701.

Conquanto tais declarações tenham reconhecido alguns direitos aos ingleses, como o direito de petição, o Habeas Corpus, a legalidade penal, dentre outros, válido ressaltar que estes foram frutos de enunciações consuetudinárias, o que resultou na gradual limitação do poder monárquico e fortalecimento do parlamento. Em razão disso, tais direitos não poderiam ser considerados como marco inicial dos direitos fundamentais em razão da não vinculação do Parlamento a estes, vez que careciam de supremacia e estabilidade (SARLET, 2015, p.43).

Demais disso, eram instrumentos destinados a garantir privilégios e prerrogativas a determinadas classes - nobreza, na Magna Charta de 1215 e Parlamento, na Bill of Rights de 1669 (SILVA, 2005, p. 545). Nesse sentido, afirma-se (DIMOULIS; MARTINS, 2012, p. 9-12) que para 
se possa falar da existência de direitos fundamentais, faz-se necessária a presença de três elementos.

O primeiro deles se refere ao Estado (moderno), justamente pelo fato de que deve haver um poder capaz de controlar seu território e de impor suas decisões. Dito isso, vê-se que a inexistência deste faz com que a proclamação daqueles direitos careça de efetividade, pois não poderiam ser exigidos e cumpridos, perdendo sua essência que é a de limitar o poder estatal. O segundo elemento essencial à consagração de direitos fundamentais é a existência de um indivíduo enquanto ser moral, independente e autônomo, o que faz com que este possa fazer buscar a tutela de seus direitos, exatamente por possuir autonomia como ente sujeito de direitos. Por último, há de se ressaltar a existência de um texto normativo que regule as relações entre o soberano e os indivíduos - que é desempenhado pelas Constituições em sentido formal, pois estas declaram e garantem certos direitos fundamentais - como norma constitucional suprema, de modo a impedir que o Estado e os indivíduos os cerceiem de maneira injustificada (força vinculante).

Diante disso, é somente a partir da Declaração de Direitos da Virgínia (1776) e da Declaração Francesa (1789) que se pode falar na consagração de direitos fundamentais de envergadura constitucional, quando se dá a positivação dos direitos inerentes ao homem, mas que até o momento estavam mais atrelados a reinvindicações políticas e filosóficas (MENDES; MÁRTIRES COELHO; GONET BRANCO, 2009, p.266). Tais declarações, apesar da identidade de conteúdo com as anteriores, possuem a peculiaridade de vincular os poderes públicos.

Por derradeiro, até 1998 na Inglaterra seria possível afirmar que não havia uma declaração nos moldes acima mencionados. Em 1990, Ronald Dworkin publicou um artigo - A Bill of Rights for Britain - aduzindo a necessidade de uma declaração que vinculasse o Parlamento inglês (DWORKIN, 1990). O problema de tal concepção era que qualquer norma que vinculasse o Parlamento seria tida como antidemocrática, na medida em que o tornaria submisso (WALDRON, 1993, p. 18).

Tal debate culmina com a aprovação da Human Rights Act em 1998. A partir disso, vê-se que é a limitação aos órgãos estatais (e aos particulares) que pode ser considerada como o aspecto peculiar que irá determinar o surgimento dos direitos fundamentais. 


\section{DAS DIMENSÕES DE DIREITOS FUNDAMENTAIS}

Os direitos fundamentais, desde o seu reconhecimento nas primeiras Declarações de Direitos, passaram por diversas transformações, seja quanto a seu conteúdo, seja quanto à sua titularidade (SARLET, 2015, p.45). Em face disso, diante da universalização e ampliação de novos direitos, quer em virtude do surgimento de novos bens merecedores de tutela, quer em razão da ampliação dos titulares desses direitos, criou-se a expressão gerações ou dimensões dos direitos fundamentais para se referir ao processo histórico de reconhecimento destes.

A terminologia atinente ao tema das gerações de direitos fundamentais costuma ser atribuída a Karel Vasak (SILVA, 2005, p. 545), ao relacionar a evolução dos direitos fundamentais aos lemas da Revolução Francesa: liberdade (primeira geração), igualdade (segunda geração) e fraternidade (terceira geração). No entanto, entende-se (BRANDÃO, 2000, p. 121-122) que a terminologia dimensão dos direitos fundamentais seja mais adequada, visto que não há como negar que o reconhecimento destes tem um caráter progressivo e complementar, bem como o caráter unitário e indivisível de tais direitos no contexto do direito interno e alienígena.

Norberto Bobbio (1992, p. 30), ao tratar da evolução histórica dos direitos fundamentais, também cunhou a expressão gerações de direitos fundamentais às máximas da Revolução Francesa (liberdade, igualdade e fraternidade), classificando-os, respectivamente, em direitos de primeira, segunda e terceira dimensão. Posteriormente, com o surgimento de novas demandas sociais e, especialmente, com a globalização e o avanço da tecnologia, fala-se em direitos de quarta e quinta dimensão (BONAVIDES, 2013, p.589-597), como se verá adiante.

Os direitos de primeira dimensão são frutos do pensamento liberal-burguês do século XVIII, reconhecidos como direitos negativos ou de não interferência, porquanto dirigidos a uma abstenção do Estado frente ao indivíduo. Cuida-se, assim, dos chamados direitos civis (vida, liberdade, igualdade formal, propriedade, segurança) e políticos (capacidade eleitoral ativa e passiva). Surgem, dessa forma, no contexto do constitucionalismo político clássico (LAFER, 2003, p. 126-127), de modo que sua proclamação se deu com as declarações de Virgínia (1776) e da França (1789), além de sua incorporação às Constituições Francesa (1791 e 1793) e Americana (1787). 
Todavia, com o advento do Estado social do pós-guerra, o Estado deixa de ter uma postura passiva para assumir uma atuação ativa, diante das diversas necessidades sociais (CARVALHO, 2008, p. 672), como resposta aos movimentos e ideias antiliberais. O ideal absenteísta do Estado liberal não respondia de maneira satisfatória os anseios sociais, obrigando, a partir de então, a adotar uma postura positiva, no sentido de satisfação das necessidades sociais. Surgem, daí, os chamados direitos de segunda dimensão, também denominados direitos sociais, econômicos e culturais, como o trabalho, a saúde e a educação - caracterizados por uma atuação positiva do Estado, já que este passa a ser provedor das necessidades públicas básicas.

Devido às diversas mutações pelas quais passaram a sociedade, em consequência das novas reivindicações do gênero humano, sobretudo em relação àquelas ocasionadas pelo impacto tecnológico, tem-se os denominados direitos de solidariedade (ou de fraternidade), caracterizados pelo deslocamento da figura individual para a coletiva, visando à proteção de grupos humanos - tutela interesses transindividuais (LAFER, 2003, p. 131), como a garantia de um meio ambiente ecologicamente equilibrado (art. 225, CR/88). No que tange a tais direitos, além da alusão aos de caráter difuso ou coletivo, há interpretações ampliativas (Cf. BEDIN, 1998, p. 73-78) que incluem o direito à autodeterminação dos povos, ao desenvolvimento, à paz e à comunicação.

Estes direitos começaram a ganhar impulso após o período da segunda guerra mundial, que eclodiu e trouxe o extermínio de vidas humanas e degradação do meio ambiente (WOLKMER, 2002, p. 17-18). No Brasil, sua proteção se deu especialmente com o advento da Lei de Ação Civil Pública (n. 7347/85), a qual disciplinou a tutela do meio ambiente, do consumidor e de demais bens de caráter artístico, histórico e cultural.

Além das três primeiras dimensões, há trabalhos atinentes a outras três, inobstante a falta de unanimidade em tais classificações. Nessa concepção, conforme a classificação proposta por Bonavides (2013, p. 589-597), os direitos de quarta dimensão (relacionados à democracia, à informação e ao pluralismo) são resultado da globalização dos direitos fundamentais e constituem a base para uma possível globalização política, da qual o direito à democracia direta e globalizada seria o mais importante deles.

Para outros autores (OLIVEIRA JÚNIOR, 2000, p. 97), a citada dimensão inclui também o direito para manipulações genéticas, o direito à 
mudança de sexo e os relacionados à biotecnologia, direitos que têm vinculação direta com a vida humana. Comungando deste entendimento, o Supremo Tribunal Federal, no voto proferido por Ricardo Lewandowski, quando do julgamento da Lei de Biossegurança que autorizava pesquisas com células embrionárias, entendeu que os direitos decorrentes da tecnologia da informação e da bioengenharia, especialmente a proteção contra manipulações genéticas, constituem direitos de quarta dimensão (STF ADI. 3510/DF. Rel. Min. Ayres Britto, Pleno, j. 29/05/2008).

No que concerne à quinta dimensão, com o intento de assegurar um lugar de destaque à paz, porquanto a percepção desta é condição para a democracia, desenvolvimento e progresso social, há o alocamento deste direito sob tal classificação, tendo em vista que esta interfere na própria efetividade dos direitos humanos/fundamentais (SARLET, 2015, p. 52). Nesse sentido, diz-se que o novo Estado de Direito das cinco gerações de direitos fundamentais vem coroar o espírito de humanismo e a proclamação da paz como direitos de quinta dimensão e vêm tirá-los da obscuridade a que antes estavam confinados como direitos de terceira dimensão (BONAVIDES, 2013, p. 589-597).

Há de se fazer ressalvas, todavia, a outros entendimentos (WOKMER, 2002, p. 21), para os quais os direitos de quinta dimensão são aqueles advindos das tecnologias da informação, do ciberespaço e da realidade virtual em geral. Por outro lado, ainda há dicção, ainda não firmada na doutrina, aos direitos de sexta dimensão. Trata-se, segundo os autores, do direito à água potável que, por ser integrante do meio ambiente ecologicamente equilibrado (art. 225, CR/88), merece ser alçado a um degrau de destaque, frente às novas necessidades humanas (FACHIN; SILVA, 2011, p. 74).

Vistas as classificações tradicionais e o posicionamento jurídico pátrio acerca deste tema, faz-se necessário lançar luzes a tal concepção, de modo a trazer reflexões adicionais às referidas nomenclaturas.

\section{DA MULTIDIMENSIONALIDADE DOS DIREITOS FUNDAMENTAIS: DA NECESSIDADE DE RELEITURA DAS DIMENSÕES DE DIREITOS FUNDAMENTAIS FRENTE ÀS NOVAS DEMANDAS SOCIAIS}


Percebeu-se, até o momento, que o constante reconhecimento do processo cumulativo e complementar de tais direitos teve como ponto de arranque a tríade jusnaturalista do século XVII. Assim, os direitos fundamentais partem de uma universalidade abstrata - extremamente limitada no que tange à sua eficácia - para uma acepção concreta e eficaz (protegidos como autênticos direitos positivos), mas não universal, posto que somente poderiam ser exigidos no âmbito espacial limitado, culminando, ao final, em uma plena realização como direitos positivos universais (BOBBIO, 1992, p. 28), notadamente pelo advento da Declaração Universal dos Direitos do Homem e do Cidadão de 1948.

Dessa forma, viu-se que os direitos de primeira, segunda e terceira dimensões estavam ligados aos postulados da Revolução Francesa igualdade, liberdade e fraternidade. Tal visão é incompleta, por não fazer alusão ao mais fundamental dos direitos e o próprio fundamento do Estado Democrático de Direito, que é a dignidade humana.

Ademais, o modelo processual atrelado até a segunda metade do século XX era estritamente individual, pois o coletivo não tinha espaço. Com o reconhecimento de direitos de dimensão coletiva - direitos transindividuais - em decorrência de não haver instrumentos aptos a tutelá-los, fez com que emergissem meios processuais que visem a assegurá-los.

Daí a necessidade do surgimento de normas aptas a alterar o paradigma de legitimidade e da coisa julgada - de modo a permitir que todos os titulares do direito sejam beneficiados pelo resultado da lide. Nesse aspecto, tem-se inicialmente o advento da Lei 4.717/65 - Lei de Ação Popular - com a previsão da coisa julgada erga omnes. Posteriormente, surgem outros instrumentos processuais que visam a tutelar os novos direitos, tais como: i) Lei da Política Nacional do Meio Ambiente (Lei 6.938/81); ii) Lei de Ação Civil Pública (Lei 7.347/85); iii) Constituição de 1988 (por todos, art. $5^{\circ}$, incisos XXXV, LXXIII, LXX, XXI; art. $8^{\circ}$, III; art. 129, III); iv) Código de Defesa do Consumidor (Lei 8.078/90); dentre outros.

Além do mais, uma visão conglobante acerca do tema faz com que se chegue à conclusão de que a leitura isolada das dimensões dos direitos fundamentais leva à errônea acepção de que se trata tão somente do reconhecimento de novos direitos, uma vez que a inserção de novos direitos faz com que haja uma releitura dos anteriormente fixados.

Sendo assim, apesar de o direito à propriedade ser considerado como de primeira dimensão, sua leitura a partir dos demais dispositivos constitucionais faz com que se perca a perspectiva isolada, já que ela 
deverá cumprir a sua função social (art. $5^{\circ}$, XXII, CR/88) - direito atrelado à segunda dimensão, uma vez que a função social da propriedade está atrelada a uma prestação à coletividade. Do mesmo modo, a igualdade não é entendida no sentido estritamente formal, mas também em seu aspecto material (Cf. ADPF 186, rel. min. Ricardo Lewandowski, j. 26-4-2012, DJE de 20-10-2014), por permitir a superação de desigualdades decorrentes de situações históricas.

Ademais, a classificação dos direitos em dimensões, apesar de estar ligada diretamente ao contexto histórico e social pelos quais passaram os direitos, não contribui sobremaneira para o aperfeiçoamento do tema. Nesse aspecto, a fragmentação dos direitos de quarta e quinta dimensões contempla, em verdade, direitos tipicamente individuais, sociais e transindividuais. Assim, "[o]s direitos decorrentes da biotecnologia e da bioengenharia geram direitos sociais, que podem dizer respeito ao consumidor quando se trata de alimentos modificados (BRANDÃO, 2000, p. 126)", bem como causar danos ao meio ambiente (direito de terceira dimensão).

Do mesmo modo, os direitos atinentes à realidade virtual (que para alguns é classificado como de quinta dimensão) podem gerar danos de cunho estritamente individual, como no caso da inserção de vírus em computador privado, ou lesões coletivas, no caso de afeto à coletividade, a exemplo de danos advindos na rede mundial de computadores.

Por outro lado, o direito à saúde é, segundo a classificação supramencionada, classificado como de segunda dimensão. Todavia, em se tratando de demandas coletivas por medicamentos, tem-se a tutela de interesses difusos ou coletivos em sentido estrito. Do aqui aferido, chega-se à conclusão de que o direito será classificado em determinada dimensão de acordo com a tutela processual conferida a tais direitos. Assim, a divisão do tema em dimensões acaba gerando um esvaziamento do instituto e do próprio conteúdo dos direitos fundamentais.

Por este e outros motivos, sem deixar de reconhecer o trabalho atinente à aludida classificação, no atual estágio da ciência, entende-se que a expressão correta acerca da evolução histórica dos direitos fundamentais e suas diversas concepções deve se referir à sua multidimensionalidade, uma vez que os direitos fundamentais formam um sistema harmônico, coerente e indissociável, fato que importa na impossibilidade de sua compartimentalização. 


\section{FUNDAMENTALIDADE MATERIAL DOS DIREITOS FUNDAMENTAIS E FUNDAMENTO DO SURGIMENTO DOS NOVOS DIREITOS}

As necessidades humanas, os problemas enfrentados hodiernamente e os conflitos ocasionados pela proliferação da tecnologia engendram a necessidade de releitura de novas formas de direitos que desafiam a sociedade contemporânea. Por serem as necessidades humanas inesgotáveis e ilimitadas no tempo e no espaço, estão estas em constante redefinição e criação (WOLKMER, 2002, p. 26). Afinal, as mudanças e o desenvolvimento das relações humanas transcendem as possibilidades do sistema, legitimando a busca por novas medidas aptas a saná-las. Qual seria, então, a fundamentação desses novos direitos no ordenamento jurídico pátrio?

Para responder a tal questionamento, imprescindível a análise do preceito constante do art. $5^{\circ}, \S 2^{\circ}$, da Constituição da República, segundo o qual os direitos e garantias fundamentais expressos nesta Carta não excluem outros decorrentes do regime e dos princípios por ela adotados, bem como dos tratados internacionais dos quais o Brasil seja parte. De acordo com alguns autores (SARLET, 2015, p. 81 e ss; CANOTILHO, 1999, p. 539 e ss), os direitos fundamentais podem ser analisados sob o sentido formal - aqueles que, por decisão explícita do legislador, foram consagrados no catálogo dos direitos fundamentais - e sob o sentido material, que, inobstante fora do rol destes, são equiparados formal e materialmente.

Quanto ao primeiro critério, chega-se a advogar a tese de que todos os direitos garantidos na Constituição são considerados fundamentais (DIMOULIS; MARTINS, 2012, p. 40-45), o que parece problemático, pois este entendimento pode trazer o consequente esvaziamento de seu conteúdo. Consigna-se, ademais, o entendimento do Supremo Tribunal Federal no sentido de que os direitos fundamentais não são somente aqueles que constam do rol do Título II da Carta Política brasileira, como ocorreu em relação ao princípio da anterioridade tributária constante do art. 150, III, b, (Cf. ADI 939-7, Rel. Min. Sidney Sanches, DJe 18/03/1994).

Quanto ao sentido material dos direitos fundamentais, José Afonso da Silva (1992, p. 174) apresenta a distinção entre os direitos implícitos (decorrem diretamente das normas explícitas) e os decorrentes do regime e das normas internacionais de que o Brasil faça parte - que se consubstanciam naqueles não implícita nem expressamente enumerados - expressão denominada por Jorge Bacelar de direitos fundamentais atípicos (GOUVEIA, 1995, p. 40). 
Em tom crítico à posição supracitada por Afonso da Silva, Flávia Piovesan (2013, p. 119-120) afirma que os direitos fundamentais decorrentes dos tratados internacionais assumidos pelo Brasil não podem ser equiparados aos direitos decorrentes do regime e dos princípios adotados pela Carta Maior, pois aqueles estão positivados - mesmo que em âmbito alienígena, enquanto estes não estão explícita nem implicitamente enunciados, com a peculiaridade de provir do regime e dos princípios adotados pela Constituição brasileira.

Diante disso, Piovesan propõe classificação concernente aos direitos fundamentais: i) expressos na Constituição; ii) consagrados em documentos internacionais que o Brasil tenha subscrito; iii) decorrentes do regime e dos princípios adotados pela República Federativa do Brasil. De outro modo, Ingo Sarlet (2015, p. 88-89) reconhece a existência dos direitos positivados (formalmente fundamentais) e os não positivados no texto constitucional (materialmente fundamentais), sendo estes últimos classificados entre direitos fundamentais implícitos e decorrentes do regime e dos princípios adotados pela Constituição.

À luz deste último critério, tendo em vista as devidas mutações ocasionadas pelo dinamismo social e pelo implemento de novas demandas, há de se reservar a possibilidade de agasalhá-los no âmbito de proteção constitucional (IRIBURE JÚNIOR, 2012, p. 230-231). No mesmo sentido, é a posição de Menelick (CARVALHO NETTO, 2003, p. 154), ao aferir que dicção do art. $5^{\circ}, \S 2^{\circ}$ da Carta Magna apresenta a noção de que a Constituição brasileira está em um processo permanente de aquisição de novos direitos. Ainda nesse contexto, diz-se que o legislador Constituinte, ao se referir aos termos "regime e princípios", quis reforçar o reconhecimento e a garantia de outros direitos que as circunstâncias temporais e as necessidades do viver em sociedade pudessem exigir (JACQUES, 1983, p. 175).

Em razão disso, é mister a tentativa de identificar critérios para um conceito material de direitos fundamentais, isto é, quais os direitos, previstos ou não na Carta Maior, que reúnem caracteres atinentes ao conteúdo (materialidade) fundamental. Desse modo, no que tange aos direitos não escritos - implícitos e decorrentes - conforme classificações acima, os primeiros são irradiados das próprias normas constitucionais expressamente reconhecidas. Isso significa que é possível extrair, do próprio texto constitucional, as luzes por eles irradiadas, sendo algo inerente ao sistema constitucional. 
Consigna-se que, no que tange ao Direito comparado, a referência aos direitos implícitos foi preconizada inicialmente na Emenda Constitucional n. 9, de 1791, à Constituição dos Estados Unidos, in verbis: "A enumeração de certos direitos na Constituição não será interpretada como excluindo ou restringindo outros direitos conservados pelo povo".

Em Portugal, a Constituição de 1976, no art. $16,1^{\circ}$ e $2^{\circ}$, em disposição similar à brasileira, afirma que os direitos consagrados em sua Lei Maior não excluem outros previstos nas leis e regras aplicáveis de Direito internacional, além da necessidade de interpretá-los e integrá-los à luz da Declaração Universal dos Direitos dos Homens. Em estudo do citado dispositivo, a doutrina portuguesa (CANOTILHO; MOREIRA, 1993, p. 137) reconhece seu caráter material, sem, contudo, apresentar suas características aferíveis.

Nesse diapasão, apesar de previsão constitucional (art. 227, caput, CR/88), o direito a alimentos vem sendo considerado como direito fundamental implícito, vez que decorre da própria dignidade humana, atrelada ao mínimo existencial (TJ-DF - AGI: 20150020227482, Rel. Carlos Rodrigues, DJe 16/02/2016).

Já em relação aos princípios decorrentes do regime adotado pela Constituição, somente poderão ser considerados fundamentais os que, não obstante fora da Carta Maior, por seu conteúdo e importância, possam ser equiparados aos enumerados no rol do Título II da Constituição (SARLET, 2015, p. 93). Ao adotar o referido critério, percebe-se a posição de reconhecer que a noção de direito fundamental erige do grau de importância que este representa à sociedade. Sob essa perspectiva, pode-se dizer que é fundamental porque sem ele a pessoa não se realiza, não convive e, às vezes, não sobrevive (SILVA, 1992, p. 172).

Feitas tais considerações, insta verificar o significado das terminologias "regime e preceitos" pelos quais o Brasil adotou. Fale-se que o aludido dispositivo diz respeito ao regime político do Estado Democrático de Direito brasileiro, referindo-se, especialmente, às dicções do Título I da Carta Política de 1988, as quais apresentam os fundamentos, objetivos e princípios concernentes às relações internacionais (SARLET, 2015, p. 9495).

Além disso, outro critério elementar referido por vários doutrinadores diz respeito à utilização da dignidade humana como parâmetro de análise à fundamentalidade material de tais direitos. Em que pese a visão cética de alguns (Cf. CANOTILHO, 1997, p. 373), especialmente na 
possibilidade de tal entendimento expulsar do catálogo material os direitos que não são relacionados diretamente à dignidade humana, é de se exaltar o importante parâmetro como critério complementar àqueles supracitados. Na mesma linha, Flávia Piovesan (2013, p. 192) considera que o referido preceito, além de valor unificador de todos os direitos fundamentais, assume papel legitimador ao reconhecimento de direitos fundamentais não previstos no texto constitucional. Há quem diga, inclusive, não ser distorcido o entendimento de que todos os demais direitos fundamentais perfazem uma categoria inclinada a carrear a aplicabilidade da dignidade humana em todas as suas dimensões (IRIBURE JÚNIOR, 2012, p. 234).

Com base nesse nobre posicionamento de considerar a dignidade humana como um dos critérios aferíveis à identificação de direitos fundamentais não previstos na Carta Maior, diversas questões recentes foram levadas ao Judiciário pátrio, especialmente no tocante à identidade genética e aos do campo dos direitos da personalidade. Nesse sentido, com fulcro no entendimento ora exarado, a jurisprudência pátria tem entendido que a dignidade humana impõe o direito à mudança de nome de pessoas que foram submetidas à cirurgia de transgenitalização, sob pena de discriminação vexatória frente à sociedade (Cf. TJ-MG 100240577822030011, Rel. Edivaldo Jorge dos Santos. DOS SANTOS, j. 06/03/2009).

Além do mais, o Superior Tribunal de Justiça, diante do preceito da dignidade humana, consagra aos netos a possibilidade de ajuizar ação declaratória de relação avoenga, em razão e o direito ao conhecimento da origem genética estar diretamente ligado à dignidade humana (Cf. STJ REsp:807849 RJ 2006/0003284-7, Rel. Min. Nancy Andrighi, DJe 06/08/2010).

Por fim, com o intuito de enriquecer o tema, pertinente conhecer o posicionamento do doutrinador lusitano Jorge Miranda (1998, p. 159), o qual estabelece outros critérios referentes à aferição material dos direitos fundamentais, quais sejam, a dignidade da pessoa humana e a integração harmônica com a Declaração Universal dos Direitos do Homem e do Cidadão. Conforme já exposto, a Constituição de Portugal, em seu artigo 16, consagra a interpretação de seus preceitos em consonância com a referida declaração.

\section{CONSIDERAÇÕES FINAIS}


Como se demonstrou na presente reflexão, a dogmática tradicional tende a conceber a evolução histórica dos direitos fundamentais por meio das chamadas dimensões dos direitos fundamentais, vez que estes foram construídos historicamente como mecanismos de contenção do poder estatal. Demais disso, as novas necessidades humanas, os problemas enfrentados hodiernamente, o aperfeiçoamento das instituições democráticas e os conflitos ocasionados pela proliferação da tecnologia lançam uma releitura das novas formas de direitos que desafiam a sociedade contemporânea.

Afinal, tendo em vista que as demandas sociais são inesgotáveis e ilimitadas no tempo e no espaço, esses novos direitos estão em constante redefinição e criação (WOLKMER, 2002, p.26), legitimando a busca por novas medidas aptas a sanar as tendências humanas.

Assim sendo, viu-se que o fundamento atinente aos novos direitos fundamentais encontra guarida no art. $5^{\circ}, \S 2^{\circ}$, da Constituição da República, uma vez que os direitos consagrados expressamente na Carta Maior não excluem outros decorrente dos princípios e do regime por ela adotados. Desse importante preceito se extrai o fundamento das novas dimensões de direitos fundamentais que vêm sendo trabalhadas pela dogmática tradicional.

Contudo, o simples enquadramento desses direitos em "novas dimensões" não contribui para sua adequada delimitação e caracterização, de modo a gerar um esvaziamento do instituto e do próprio conteúdo dos direitos fundamentais. Além disso, percebe-se que, adotando a aludida classificação, o enquadramento dos direitos fundamentais em determinada dimensão pode ser percebido por seu modo de tutela.

A título de exemplo, o direito à saúde isoladamente considerado, como ocorre quando determinada pessoa individualmente vai até o Poder Judiciário com o intuito de obrigar o Poder Executivo a fornecer medicamentos, tratar-se-á de direito de segunda dimensão. Por outro lado, em se tratando de demanda coletiva de fornecimento de medicamentos por meio de uma ação civil pública, ter-se-á um direito relativo à terceira dimensão.

Em razão disso, sem deixar de reconhecer o mérito relativo à referida nomenclatura, o presente artigo vem lançar novas reflexões acerca do tema, de modo a sugerir a utilização da expressão multidimensionalidade dos direitos fundamentais, tendo em vista que estes formam um sistema harmônico, coerente e indissociável, fato que importa na impossibilidade de sua compartimentalização. 
Ademais, o modelo jurídico emergido das duas primeiras dimensões não dava espaço para tratar do coletivo, uma vez que o foco era a defesa do direito individual. Por isso, os instrumentos processuais à época visavam proteger esse tipo de conflito. No entanto, com os direitos de cunho supraindividual, especialmente em meados do século XX, começaram a se revelar insuficientes para salvaguardar os interesses coletivos, diante da nova realidade social então surgida.

Assim, havia o reconhecimento de novos direitos, mas não existiam meios aptos a assegurá-los. Cappelletti já apontava a necessidade de se tutelar direitos da chamada sociedade de massa, lugar em que despontavam conflitos envolvendo coletividades. Daí a emergência em se criar normas que alterassem tanto a legitimidade ativa quanto os efeitos da coisa julgada.

Diante de todo o exposto, percebe-se que o processo é instrumento de efetivação dos direitos fundamentais, de modo e na medida em que novos direitos vão sendo reconhecidos e efetivados no ordenamento jurídico, o processo há de se adequar às novas necessidades sociais, como ferramenta garantista e essencial do Estado Democrático de Direito.

\section{REFERÊNCIAS}

BEDIN, Gilmar A. Os direitos do homem e o neoliberalismo. 2.ed. Ijuí: Unijuí, 1998.

BOBBIO, Norberto. A era dos direitos. Rio de Janeiro: Elsevier, 1992.

BONAVIDES, Paulo. Curso de direito constitucional. 28. ed. São Paulo: Malheiros, 2013.

BRANDÃO, Paulo de T. A tutela judicial dos "Novos" direitos: em busca de uma efetividade para os direitos típicos da cidadania. Florianópolis: CPGD, 2000 (Tese de Doutorado em Direito). Disponível em: < https://repositorio.ufsc.br/handle/123456789/79158>. Acesso em 13/06/2017.

CANOTILHO, José Joaquim Gomes. Direito constitucional e teoria da constituição. 4. ed. Coimbra: Almedina, 1997.

COMPARATO, Fábio Konder. A afirmação histórica dos direitos humanos. São Paulo: Saraiva, 1999.

DIMOULIS, Dimitri, MARTINS, Leonardo. Teoria geral dos direitos fundamentais. 4. ed. São Paulo: Atlas, 2012.

DWORKIN, Ronald. A Bill of Rights for Britain. London: Chatto \& Windus, 1990. 
FACHIN, Zulmar; SILVA, Deise Marcelino da. Acesso à Água Potável: direito fundamental de sexta dimensão. Campinas: Millennium, 2011.

GOUVEIA, Jorge Barcelar. Os direitos fundamentais atípicos. Lisboa: Aequitas, 1995.

IRIBURE JÚNIOR, Hamilton da Cunha. Os Direitos Fundamentais na Ordem Constitucional. Jurisdição Constitucional. In: SARLET, Ingo Wolfgang; LEITE, George Salomão (coords). Jurisdição Constitucional, Democracia e Direitos Fundamentais: Estudos em homenagem ao Ministro Gilmar Ferreira Mendes. Salvador: Editora Juspodivm, 2012. 